\title{
CBP Regimen
}

National Cancer Institute

\section{Source}

National Cancer Institute. CBP Regimen. NCI Thesaurus. Code C9783.

A chemotherapy regimen consisting of carmustine, cyclophosphamide, and cisplatin that may be used in the treatment of breast cancer. 